\section{THE SWIFT FOX}

On 26 July 1996 while coming home from Kyle, 8 miles south and 6 miles west, I noticed what looked like a cat, lying flat on the edge of a summer fallow field, just across the ditch.

On getting closer I noted the ears were a little large and the nose a little long for a cat. After driving a quarter mile past, I turned around and drove slowly by again, and realized that it was either a Swift Fox or a young Coyote.

Again I kept going until a half mile past, then turned and drove slowly until just by the animal when I stopped. Now the animal stood up, took a few steps then stopped and looked at me, and having seen Swift Foxes before, I am certain that this was one.

The colour was very much like a Coyote, with a black-tipped tail but features of a fox, and the size of a cat.

The animal had dug out both ends of a culvert that had been buried with blow dirt for years, and had been there for some time.

I saw Lloyd Sather, the owner of the land, and asked if he had seen the animal and if he knew that it was a Swift Fox. He replied that he had seen it a few times, but thought that it was a fox that was not doing well.

Sig Jordheim, Kyle, SK.

\section{STRANGE BEHAVIOUR OF A FEMALE AMERICAN ROBIN}

5:30 a.m., 3 May 1996. I have just awakened and am lying in bed wondering what woke me. I hear a noise something like a light tap and then a brushing sound. I think it is the furnace coming on and the pipes expanding. No. It's also not like the noise you hear at $-40^{\circ}$ when the house contracts with the cold. I lie in bed and listen. The sound is intermittent and varying in intensity. The next time I hear the noise, I get up and sit at the kitchen table where it seems to be coming from down the hall. I go to the first bedroom and then the second. Then I hear and see something hit the window. When I look out, I see a female American Robin sitting on a spruce branch about two feet away. She flies at the window, hits it and flies back to the branch. I find this unusual as I thought that only males would defend their territory. This Robin seems to be seeing its reflection in the window and to be trying to chase it away.

I now close the blinds and go back to bed. The Robin continues her attack. This time I get up and remove the screen. This does not work either. I get up again and pull the blinds up to the top. The attack continues. I get up and open the window so the angle of reflection is different. The Robin still attacks the window, so I get up, close the window and put on the light, but this does not work. When she is about to attack again, I turn the light off and on as fast as I can several times. She still attacks, even with the light blinking. Off and on all day long the attack continues. 